\title{
The challenge of measuring pain
}

\author{
Os desafios de mensurar a dor
}

Pain is an experience described in terms of sensorial, motivational, and cognitive characteristics and, many times, with emotional sequelae. That is why the use of many pain measurements, such as the multidimensional scales and questionnaires, result, partially, from the recognition and evaluation of its different components and dimensions. However, in the past, a myriad of studies on the subject and its analgesia have considered pain as a unitary dimension, varying only in intensity. But, as the results of experimental studies can depend on different dimensions of the symptom at the moment of the evaluation, pain can be felt in a peculiar way by each patient. Using a simple measurement of the pain sensation can introduce significant variability in the mechanisms and in the effective pain treatment ${ }^{1}$.

What do patients understand when describing the magnitude of the pain they are feeling? Do they refer to the sensorial intensity, to the presence of specific sensorial qualities, or to their suffering, anxiety, anguish? Would the pain records be usually associated with one of these dimensions, or do their meaning vary among individuals? If the study of the pain sensation needs to have a scientific basis, it is essential to measure it. For example, in case there is the need to know the efficacy of different analgesic drugs, we need numbers, comparable objective data, so, over time, we can say if the pain has somehow decreased. Besides the importance of knowing if a drug has reduced the intensity of pain, it is also important to know if the drug has especially reduced the quality of the discomfort as the burning pain, or if the feelings of discomfort and displeasure, associated with pain, have disappeared in some way. However, the parameters that describe the quality of pain are not always universal, but subjective, idiosyncratic, because they depend on the cultural repertoires and individual patterns.

Now, usually, the assessment of clinical pain is based on the oral reports or on the descriptors commonly used by the patients to describe the pain they are experiencing at that moment. One of the problems is related to the extent that these commonly used oral descriptors share the same meaning in the main dimensions of pain because one pain descriptor can have more than one meaning. This led, for example, to the development of the McGill pain assessment questionnaire as an instrument to assess the sensorial, emotional, and evaluative qualities of pain, together with several other aspects, such as intensity, pattern, and location. This questionnaire has been translated and standardized for different cultures, races, and gender, due to the huge variability in the meaning of the different pain descriptors used by the patients to describe both acute and chronic clinical pain. However, the idiosyncratic variability of the meanings attributed to pain cannot and should not be regarded as an impeditive to the development of methods that allow to investigate it objectively. Currently, it is known that both the relief and cure, the feeling of being relieved/cured are completely different concepts that need to be observed, so the treatment of the patient with pain reaches its full objectives ${ }^{2}$.

In fact, apparently, we all agree that pain is a subjective, personal and multidimensional experience that involves psychological, behavioral, emotional, cognitive and sensorial dimensions. Since it is a multifaceted phenomenon, pain is also affected by past experience and culture. Thus, measure the intensity of pain is of utmost importance for the researchers and physicians because its measurement is essential to evaluate the methods of control. Pain assessment/measurement is a fundamental prerequisite for effective treatment and management. Since pain is a genuinely subjective experience, only those that feel it can determine its severity and the adequate relief. In other words, only the patient's perspective is the correct. Therefore, its self-assessments are most precise and trustworthy. As a consequence, it is reasonable to ask if such phenomenon can be assessed or measured. Since pain is a subjective experience, it is only possible to assess or measure it by means of the several responses or reactions manifested by those that experience $\mathrm{it}^{3}$.

However, which aspect of pain must be primarily considered, assessed or measured? Its intensity or its varied hedonic components? To this end, it is essential to define or to clarify the meaning of the assessment and measurement terms in the context of pain.

Renato Leonardo de Freitas

Universidade de São Paulo, Faculdade de Medicina de Ribeirão Preto, Coordenador do Centro Multiusuário de Neuroeletrofisiologia e do Laboratório de Dor \& Emoçóes, Ribeirão Preto, SP, Brasil. E-mail: defreitas.rl@gmail.com

José Aparecido da Silva

Universidade de São Paulo, Faculdade de Filosofia Ciências e Letras, Ribeirão Preto, SP, Brasil E-mail: jadsilva@ffclrp.usp.br

( ) Sociedade Brasileira para o Estudo da Dor 


\section{REFERENCES}

1. Da Silva JA, Ribeiro-Filho NP. Avaliaçăo e mensuração da dor: pesquisa, teoria e prática. Ribeirăo Preto: FUNPEC Editora; 2006.
2. Da Silva JA, Ribeiro-Filho NP, Matsuhima EH. Mensurando o quinto sinal vital: a dor. Ribeirão Preto: FUNPEC-Editora; 2010. 144p.

3. Da Silva JA, Ribeiro-Filho NP. Avaliaçấo e mensuraçấo de dor clínica. Ribeirăo Preto: Livreto educativo, FUNPEC Editora; 2014.

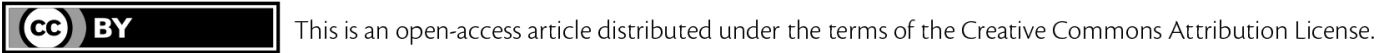

